\title{
Antagonism of lateral amygdala alphal-adrenergic receptors facilitates fear conditioning and long-term potentiation
}

\author{
Stephanie C. Lazzaro, ${ }^{1,4}$ Mian Hou, ${ }^{1}$ Catarina Cunha, ${ }^{1}$ Joseph E. LeDoux ${ }^{1,2,3}$ and \\ Christopher K. Cain ${ }^{1,2,4}$ \\ ${ }^{1}$ Center for Neural Science, New York University, New York, New York 10003, USA; ${ }^{2}$ Emotional Brain Institute at the Nathan
Kline Institute for Psychiatric Research, Orangeburg, New York 10962, USA; ${ }^{3}$ Department of Child and Adolescent Psychiatry,
New York University, New York, New York 10003, USA
}

\begin{abstract}
Norepinephrine receptors have been studied in emotion, memory, and attention. However, the role of alphal-adrenergic receptors in fear conditioning, a major model of emotional learning, is poorly understood. We examined the effect of terazosin, an alphal-adrenergic receptor antagonist, on cued fear conditioning. Systemic or intra-lateral amygdala terazosin delivered before conditioning enhanced short- and long-term memory. Terazosin delivered after conditioning did not affect consolidation. In vitro, terazosin impaired lateral amygdala inhibitory postsynaptic currents leading to facilitation of excitatory postsynaptic currents and long-term potentiation. Since alphal blockers are prescribed for hypertension and posttraumatic stress disorder, these results may have important clinical implications.
\end{abstract}

Although norepinephrine (NE) has been widely studied as an important modulator of memory and emotion, comparatively little is known about the role of NE in amygdala-dependent Pavlovian fear conditioning, a major model for understanding the neural basis of fear learning and memory. In fear conditioning, an emotionally neutral conditioned stimulus (CS; i.e., tone) is temporally paired with an aversive unconditioned stimulus (US; i.e., footshock). After very few pairings, a lasting, robust CS-US association is acquired, and the CS elicits stereotypical defensive responses, including behavioral freezing (Blanchard and Blanchard 1969; Bolles and Fanselow 1980).

The lateral nucleus of the amygdala (LA) is a key structure underlying fear conditioning (LeDoux 2000). Convergence of CS and US information in LA is believed to play an important role in initiating synaptic plasticity. Long-term potentiation (LTP)-like changes in LA CS processing are critical for fear memory storage (LeDoux 2000; Blair et al. 2001; Maren 2001; Walker and Davis 2002). LA receives auditory CS inputs from the thalamus and cortex and connects directly and indirectly with the central nucleus of the amygdala to control expression of Pavlovian fear responses.

Of the noradrenergic receptor subtypes, alpha1 receptors have received the least attention in fear conditioning. LA receives NE-containing inputs from the locus coeruleus that fire tonically and phasically in response to aversive stimuli like footshock (Pitkänen 2000; Tanaka et al. 2000; Aston-Jones and Cohen 2005). Alpha1-adrenergic receptors are expressed in LA, most likely on both excitatory and inhibitory neurons (Jones et al. 1985; Domyancic and Morilak 1997). Alpha1 receptor activation stimulates GABA-mediated miniature inhibitory postsynaptic currents in LA (Braga et al. 2004), suggesting that alpha1 receptors contribute to inhibition in fear conditioning

\footnotetext{
${ }^{4}$ Corresponding authors.
}

E-mail slazzaro@cns.nyu.edu; fax (212) 995-4011.

E-mail cc110@nyu.edu; fax (212) 995-4011.

Article is online at http://www.learnmem.org/cgi/doi/10.1101//m.1918210. pathways. Several elegant experiments recently demonstrated that LA inhibition gates synaptic plasticity necessary for fear conditioning, and this inhibitory gate can be influenced by neuromodulators including NE (Stutzmann and LeDoux 1999; Shumyatsky et al. 2002; Bissière et al. 2003; Shaban et al. 2006; Shin et al. 2006; Tully et al. 2007). However, the role of alpha1 receptor activity in gating amygdala LTP and fear learning has never been examined.

We hypothesized that alpha1 blockers would facilitate fear learning, possibly by impairing LA inhibition and facilitating LA LTP. To test this hypothesis, we injected rats with terazosin, a selective alpha1-adrenergic receptor antagonist, systemically or directly into LA before or after fear conditioning. We examined in vitro the effect of terazosin on LA pyramidal cell inhibitory postsynaptic currents (IPSCs) and excitatory postsynaptic currents (EPSCs) in response to fiber stimulation of the thalamic CS input pathway to LA, as well as the effect of terazosin on LA LTP in this same pathway. We found that intra-LA terazosin facilitated fear conditioning when injected before but not after training. We also found that terazosin impaired IPSCs in LA pyramidal cells, leading to facilitated EPSCs and LTP.

Behavioral experiments were conducted on adult, male Sprague-Dawley rats (Hilltop Laboratory Animals) weighing approximately $300 \mathrm{~g}$ upon arrival. Rats were individually housed, maintained on a $12 / 12 \mathrm{~h}$ light/dark schedule, and allowed free access to food and water. Testing was conducted during the light phase. All procedures and experiments were approved by NYU's Animal Care and Use Committee.

For systemic injections, terazosin ( $20 \mathrm{mg} / \mathrm{kg}$; Sigma) was dissolved in saline and injected intraperitoneally (i.p.) 30 min prior to conditioning in $1 \mathrm{~mL} / \mathrm{kg}$ volume. For bilateral infusions, terazosin $(125 \mathrm{ng} / 0.25 \mu \mathrm{L})$ was dissolved in aCSF and infused into the LA at $0.1 \mu \mathrm{L} / \mathrm{min} 30 \mathrm{~min}$ prior to or immediately after fear conditioning. Bilateral guide cannulae (22 gauge; Plastics One) aimed at LA ( $-3.3 \mathrm{~mm}$ anterior, $5.2 \mathrm{~mm}$ lateral, $-7 \mathrm{~mm}$ dorsal to bregma) were surgically implanted as previously described (Sotres-Bayon et al. 2009). Rats were given at least $7 \mathrm{~d}$ to recover 
from surgery before testing. For infusions, dummy cannulae were removed, and infusion cannulae (28 gauge, $+1 \mathrm{~mm}$ beyond guides) were inserted into guides. Infusion cannulae were connected to a $1.0 \mu \mathrm{L}$ Hamilton syringe via polyethylene tubing. Infusion rate was controlled by a pump (PHD22/2000; Harvard Apparatus), and infusion cannulae were left in place for an additional 60 sec to allow diffusion of the solution away from the cannula tip, then dummy cannulae were replaced. Upon completion of the experiment, rats were euthanized, brains removed, and cannulae placements verified histologically as previously described (Sotres-Bayon et al. 2009).

Two contexts (A and B) were used for all testing as previously described (Schiller et al. 2008). The grid floors in Context B were covered with black Plexiglas inserts to reduce generalization. No odors were used and chambers were cleaned between sessions. CSs were $30 \mathrm{sec}, 5 \mathrm{kHz}, 80 \mathrm{~dB}$ tones, and USs were 1 sec, $0.8 \mathrm{~mA}$ scrambled electric footshocks. Experiments consisted of two phases separated by $48 \mathrm{~h}$ : (1) fear conditioning in Context A and (2) long-term memory (LTM) test in Context B. On Day 1, rats were placed in Context A, allowed 5 min to acclimate, and then received three CS-US pairings separated by variable 5 min ITIs. On Day 3, rats were placed in Context B and allowed $5 \mathrm{~min}$ to acclimate before receiving one CS-alone presentation.

The index of fear in behavioral experiments was "freezing," the absence of all non-respiratory movement (Blanchard and Blanchard 1971; Fanselow 1980). Following testing, freezing was manually scored from DVDs by a scorer blind to group specification. Graphs represent group means \pm SEM. Statistical analysis was conducted with GraphPad Prism.

Whole-cell electrophysiological recordings were obtained from LA pyramidal cells using in vitro coronal slices from rats aged P21-P30 d as described in Cunha et al. (2010). Terazosin was bath-applied for $10 \mathrm{~min}$ to achieve stable responses before testing. The cells were voltage-clamped using an Axopatch 200B amplifier at $-35 \mathrm{mV}$ for recording EPSCs and IPSCs. Synaptic responses were evoked with sharpened tungsten bipolar stimulating electrodes. Internal capsule fibers containing thalamic afferents were stimulated for paired-pulse facilitation (PPF) (ISI $=50$ msec; $0.1 \mathrm{~Hz}$ ) using a photoelectric stimulus isolation unit with a constant current output. Cells were rejected if access resistance (8-26 $M \Omega$ ) changed more than 15\%. Signals were filtered at $2 \mathrm{kHz}$ and digitized (Digidata $1440 \mathrm{~A}$; Axon Instruments), and peak amplitude, 10\%-90\% rise time, and IPSC decay time constants were analyzed offline using pCLAMP10.2 software (Axon Instruments).

Brain slices for LTP experiments were prepared from rats aged $3-5 \mathrm{wk}$ as in Johnson et al. (2008) and maintained on an interface chamber at $31^{\circ} \mathrm{C}$. Glass recording electrodes (filled with aCSF, 5 $\mathrm{M} \Omega$ resistance) were guided to LA neurons. Bipolar stainless steel stimulating electrodes $(75 \mathrm{k} \Omega$ ) were positioned medial to LA in internal capsule fibers. Orthodromic synaptic potentials were evoked via an isolated current generator (Digitimer; $100 \mu \mathrm{sec}$ pulses of $0.3-0.7 \mathrm{~mA})$. Evoked field potentials were recorded with an Axoclamp 2B amplifier and Axon WCP software (Axon Instruments). Data were analyzed offline using WCP PeakFit (Axon Instruments). LTP was measured as a change in evoked field potential amplitude.

Baseline responses were monitored at $0.05 \mathrm{~Hz}$ for $30 \mathrm{~min}$ with a stimulus intensity of $40 \%-50 \%$ of maximum fEPSP before LTP induction. Terazosin $(10 \mu \mathrm{M})$ was superfused for $15 \mathrm{~min}$, and then LTP was elicited by three tetanus trains $(100 \mathrm{~Hz} \times 1 \mathrm{sec}$, 3 min ITI) with the same intensity and pulse duration as the baseline stimuli. In one experiment, picrotoxin (PTX; $75 \mu \mathrm{M}$ ) was present in the perfusion solution to block fast GABAergic signaling.

\section{Terazosin facilitates acquisition, but not consolidation, of fear conditioning}

We first examined the effect of terazosin, injected systemically 30 min before training, on fear learning and memory (Fig. 1A). Learning and short-term memory effects were assessed as differences in freezing during the second and third CSs of the three trial acquisition sessions. LTM effects were assessed as differences in freezing during the drug-free expression test CS $48 \mathrm{~h}$ after training. Although systemic terazosin caused sedation and reduced locomotion in some rats, it also increased CS-elicited freezing relative to controls, suggesting a learning facilitation. Freezing was distinguished from sedation by differences in posture and whisker tension. Two-way ANOVA of freezing scores during training revealed a significant effect of the group $\times$ trial interaction $\left(F_{(2,34)}=3.06, P<0.05\right)$, and post-hoc Bonferroni tests showed a significant difference in freezing for the second $(P<0.01)$ and third $(P<0.01)$ CSs. Freezing was significantly elevated in terazosin-treated rats during the drug-free LTM test $\left(t_{(1,17)}=\right.$ $3.09, P<0.01)$.
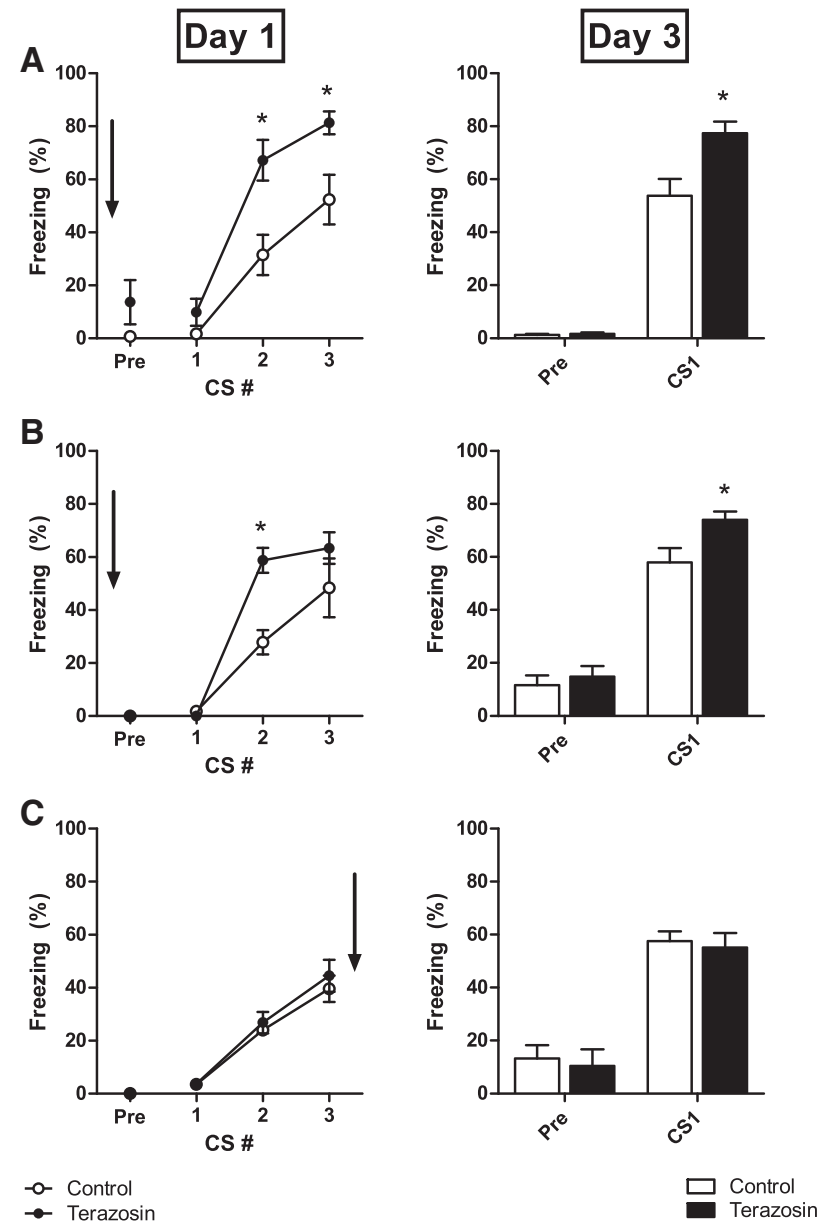

Figure 1. Pre-training terazosin facilitates conditioned fear learning when injected systemically or directly into LA. (A) Pre-CS- and CS-elicited freezing behavior during fear conditioning (left) and during a test CS $48 \mathrm{~h}$ after fear conditioning (right). Terazosin $(n=10)$ or saline $(n=9)$ was injected i.p. $30 \mathrm{~min}$ before conditioning. (B) Identical experiment except terazosin $(n=8)$ or aCSF $(n=7)$ was microinfused into LA 30 min prior to fear conditioning. (C) Identical experiment except terazo$\sin (n=6)$ or aCSF $(n=6)$ was microinfused into LA immediately after fear conditioning. Arrows indicate when drug treatment occurred. $\left({ }^{*}\right)$ $P<0.05$ versus control. 
We next infused terazosin directly into LA prior to fear conditioning to localize the drug effect and minimize concerns about nonspecific effects (sedation) associated with systemic injections. Intra-LA terazosin facilitated fear learning and LTM relative to control rats (Fig. 1B). Two-way ANOVA of freezing scores during training revealed a significant group $\times$ trial interaction effect $\left(F_{(2,26)}=4.73, P<0.05\right)$, and post-hoc Bonferroni tests showed a significant difference in freezing for the second CS $(P<0.01)$. For the LTM test, intra-LA terazosin-treated rats froze more than control rats $\left(t_{(1,9)}=2.556, P<0.05\right)$.

To differentiate between potential learning versus memory consolidation effects, we infused terazosin into LA immediately after fear conditioning in separate rats (Fig. 1C). Freezing was similar for terazosin- or vehicle-treated rats at the LTM test $\left(t_{(1,8)}=0.37\right)$, suggesting that terazosin facilitates learning, but not consolidation, of fear conditioning.

\section{Terazosin facilitates LTP in LA, most likely by impairing local inhibition}

We first evaluated the effect of terazosin on thalamo-LA EPSCs and IPSCs. Synaptic current traces of an LA pyramidal cell $(n=11)$ under applied terazosin and control conditions are shown in Figure 2A. An application of $10 \mu \mathrm{M}$ terazosin significantly decreased IPSCs $80.7 \% \pm 17.2 \%(\mathrm{pV}=0.013)$ and led to PPF of EPSCs $64.3 \% \pm 14.5 \%(\mathrm{pV}=0.006)$.

We next evaluated the effect of terazosin on thalamo-LA LTP induction with and without PTX. Without PTX, terazosin facilitated LTP (Fig. 2B). Two-way ANOVA of evoked responses post-LTP-induction showed a significant effect of the group $\times$ time interaction $\left(F_{(29,319)}=5.97, P<0.01\right)$ and time $\left(F_{(29,319)}=\right.$ 1.71, $P<0.05$ ). With PTX present (Fig. 2C), terazosin slightly impaired LTP, again showing a significant effect of interaction $\left(F_{(29,290)}=1.63, P<0.05\right)$ and time $\left(F_{(29,290)}=1.82, P<0.01\right)$. We also conducted identical LTP experiments in the cortex $\rightarrow$ LA pathway (stimulating external capsule), and terazosin failed to facilitate LTP without PTX and produced a modest impairment with PTX (data not shown). This null effect in the cortical pathway highlights the importance of the thalamic pathway in fear conditioning and suggests that alpha1 receptors mainly constrain thalamo-LA plasticity underlying memory formation.

Noradrenergic modulation of memory and anxiety has been studied for decades (Gray 1978; Davis et al. 1979; Redmond and Huang 1979). However, less is known about the role of NE in Pavlovian fear conditioning, a major model for understanding the biological basis of memory and generation of normal and pathological fear. Of the major noradrenergic receptor classes, alpha1 receptors have received less attention in studies of memory and fear than both the beta and alpha2 receptors. Because alpha1 receptors are strongly expressed in LA, a key region of plasticity in fear conditioning, we chose to examine the effects of terazosin on amygdala-dependent Pavlovian fear conditioning and its underlying synaptic processes. We found that systemic and intra-LA terazosin significantly enhanced fear learning without affecting memory consolidation. Terazosin also facilitated synaptic plasticity in an important LA fear conditioning pathway, most likely by impairing local GABAergic inhibition. These findings provide important insight into the neuromodulatory mechanisms affecting fear learning and may have important clinical implications.

We initially investigated the role of alpha1 receptors in fear conditioning using the alpha1 blocker prazosin injected systemically before training (Cain et al. 2006). Prazosin enhanced CSelicited freezing within the training session and during the drug-free LTM test, suggesting that alpha1 receptors contribute to a constraining process in fear conditioning. We switched to terazosin in these studies because it is approximately 25 times more soluble than prazosin and more selective for the alpha1 receptors, although slightly less potent (Achari and Laddu 1992). Thus, terazosin was better for investigating alpha1 contributions to brain processes important for fear conditioning. Like prazosin, we found that systemic terazosin facilitated CS-elicited freezing both within the training session and the drug-free LTM test (Fig. 1A). It is important to note that terazosin at the dose tested $(20 \mathrm{mg} /$ $\mathrm{kg}$ ) did appear to induce sedation in some rats, possibly confounding withinsession freezing scores.

To localize terazosin effects to a brain site and circumvent concerns about nonspecific systemic drug effects, we infused terazosin directly into LA before fear conditioning. Again, terazosin enhanced CS-elicited freezing during 
training and during the drug-free LTM test (Fig. 1B). There were no signs of sedation with intra-amygdala infusions. The withinsession enhancement of freezing suggests that LA alpha1 receptors normally act to constrain learning-related processes. NE, however, has been strongly implicated in consolidation processes with other fear-related behavioral paradigms such as inhibitory avoidance (Ferry and McGaugh 2008). Thus, we directly examined the contribution of LA alpha1 receptors to consolidation of fear conditioning by infusing terazosin immediately after training (Fig. 1C). We found no significant effect on CS-elicited freezing during the LTM test. Together, our findings implicate LA alpha1 receptors in a process that constrains acquisition, but not consolidation, of Pavlovian fear conditioning.

Although alpha1 receptors have never been directly examined in a cue fear conditioning procedure, amygdala-alpha1 receptor activity has been implicated in consolidation of inhibitory avoidance (McGaugh 2004). We do not believe that our findings contradict the avoidance findings. While the two procedures are related, they represent different forms of learning that depend on different brain regions. Fear conditioning is a Pavlovian procedure in which animals learn associations between environmental stimuli but have no control over their delivery. Inhibitory avoidance has an instrumental component-the animal withholds responses that lead to shock delivery. Additionally, whereas Pavlovian conditioning critically depends on LA for learning and memory, inhibitory avoidance appears to depend on LA mainly for modulation of consolidation processes taking place outside of the amygdala (McGaugh et al. 2002). It remains possible that LA alpha1 receptors can contribute both to acquisition of Pavlovian fear conditioning and consolidation of inhibitory avoidance. Future studies will be necessary to disentangle the exact contribution of LA alpha1 receptors to these two fear-related learning paradigms. One possibility is that alpha1 receptors on different neuron types (excitatory vs. inhibitory) or different populations of excitatory neurons explains the differential effects of alpha1 blockers in the two paradigms. This dissociation of noradrenergic contributions to fear conditioning and inhibitory avoidance is also seen with manipulations of beta-adrenergic receptors, where the antagonist propranolol blocks consolidation of inhibitory avoidance (McGaugh et al. 2002) but not fear conditioning (Lee et al. 2001; Debiec and LeDoux 2004; Bush et al. 2010).

Two ways NE may modulate fear acquisition have been identified. First, NE may amplify Hebbian mechanisms within pyramidal neurons that acquire plastic changes underlying conditioning (Bailey et al. 2000; Hu et al. 2007). Second, NE may suppress feedforward inhibition, effectively lowering the depolarization threshold in postsynaptic pyramidal cells necessary for inducing learning-related plasticity (Tully et al. 2007; Ehrlich et al. 2009). LA alpha1-adrenergic receptors appear to be expressed on both excitatory pyramidal neurons and local GABAergic inhibitory neurons and thus may be positioned to affect fear conditioning in either manner. Although our behavioral findings seem more consistent with the second mechanism, we directly examined the effect of terazosin on LA synaptic currents and LTP in vitro to relate our behavioral findings to synaptic processes in a known fear conditioning pathway.

Electrophysiological recordings were made in LA in response to stimulation of the internal capsule, a fiber pathway known to carry thalamic sensory afferents relaying auditory CS information (Weiskopf and LeDoux 1999). NE-containing locus coeruleus fibers have been shown to reach the amygdala via the internal capsule (Jones and Moore 1977) and likely release NE during stimulation, especially high-frequency stimulation (Bailey et al. 2000). Whole-cell voltage clamp recordings indicated that terazosin impaired IPSCs leading to enhanced EPSCs with paired stimulation. Using field potential recordings in the same pathway, we found that terazosin led to LTP with a tetanic stimulation protocol that produced only short-term potentiation in control slices. Finally, we conducted an identical LTP experiment except that PTX was included in the bath to block GABAergic inhibition. With PTX present, terazosin failed to facilitate LA LTP and instead produced a modest impairment. Identical experiments in the cortex $\rightarrow$ LA pathway (stimulating external capsule) failed to show LTP facilitation with terazosin (data not shown). Together, these findings are consistent with the hypothesis that the predominant role of LA alpha1-adrenergic receptor activity is to enhance feed-forward inhibition in the thalamic pathway and constrain plasticity related to fear conditioning. Consistent with our findings, alpha1 receptor activity has previously been reported to participate in feed-forward inhibition in LA (Braga et al. 2004). Our PTX experiment suggests that alpha1 receptors on pyramidal cells may actually enhance Hebbian LTP processes, but under normal conditions this contribution appears to be overshadowed by their contribution to inhibitory gating.

Our results suggest that alpha1-adrenergic receptor activity in LA contributes to feed-forward inhibition and constrains fear learning. Alpha1-adrenergic receptor antagonists, like prazosin and terazosin, appear to disinhibit plasticity in LA fear conditioning pathways even when given systemically. These results demonstrate another mechanism whereby NE neuromodulation can powerfully affect learning and fear. These same alpha1 blockers are commonly prescribed to combat both hypertension and nightmares associated with PTSD. Our findings suggest that clinicians should be especially aware of patients subjected to trauma while taking alpha1 blockers, as this may lead to stronger fear learning and possible exacerbation of existing fear-related disorders.

\section{Acknowledgments}

We thank Claudia Farb and Sneh Kadakia for help with histology. Funding for these experiments was contributed by RO1 MH046516, R37 MH38744, P50 MH08911 to J.E.L., and F32 MH077458 to C.K.C.

\section{References}

Achari R, Laddu A. 1992. Terazosin: A new alpha adrenoceptor blocking drug. J Clin Pharmacol 32: 520-523.

Aston-Jones G, Cohen JD. 2005. An integrative theory of locus coeruleus-norepinephrine function: Adaptive gain and optimal performance. Annu Rev Neurosci 28: 403-450.

Bailey CH, Giustetto M, Huang YY, Hawkins RD, Kandel ER. 2000. Is heterosynaptic modulation essential for stabilizing Hebbian plasticity and memory? Nat Rev Neurosci 1: 11-20.

Bissière S, Humeau Y, Lüthi A. 2003. Dopamine gates LTP induction in lateral amygdala by suppressing feedforward inhibition. Nat Neurosci 6: $587-592$.

Blair HT, Schafe GE, Bauer EP, Rodrigues SM, LeDoux JE. 2001. Synaptic plasticity in the lateral amygdala: A cellular hypothesis of fear conditioning. Learn Mem 8: 229-242.

Blanchard RJ, Blanchard DC. 1969. Passive and active reactions to fear-eliciting stimuli. J Comp Physiol Psychol 68: 129-135.

Blanchard RJ, Blanchard DC. 1971. Defensive reactions in the albino rat. Learn Motiv 2: 351-362.

Bolles RC, Fanselow MS. 1980. A perceptual-defensive-recuperative model of fear and pain. Behav Brain Sci 3: 291-323.

Braga MF, Aroniadou-Anderjaska V, Manion ST, Hough CJ, Li H. 2004. Stress impairs alpha (1A) adrenoceptor-mediated noradrenergic facilitation of GABAergic transmission in the basolateral amygdala. Neuropsychopharmacology 29: 45-58.

Bush DEA, Caparosa EM, Gekker A, LeDoux JE. 2010. Beta-adrenergic receptors in the lateral nucleus of the amygdala contribute to the acquisition but not consolidation of auditory fear conditioning. Front Behav Neurosci 4: 154. doi: 10.3389/fnbeh.2010.00154. 
Cain CK, Bush DE, LeDoux JE. 2006. Prazosin, an alpha1-adrenergic receptor antagonist enhances acquisition and impairs extinction of Pavlovian cue fear. In Proceedings from the 2006 Neuroscience Meeting. Society for Neuroscience, Atlanta, GA.

Cunha C, Monfils MH, LeDoux JE. 2010. GABAc receptors in the lateral amygdala: A possible novel target for the treatment of fear and anxiety disorders? Front Behav Neurosci 4: 6. doi: 10.3389/ neuro.08.006.2010.

Davis M, Redmond DE Jr, Baraban JM. 1979. Noradrenergic agonists and antagonists: Effects on conditioned fear as measured by the potentiated startle paradigm. Psychopharmacology (Berl) 65: 111-118.

Debiec J, LeDoux JE. 2004. Disruption of reconsolidation but not consolidation of auditory fear conditioning by noradrenergic blockade in the amygdala. Neuroscience 129: 267-272.

Domyancic AV, Morilak DA. 1997. Distribution of alpha1A adrenergic receptor mRNA in the rat brain visualized by in situ hybridization. J Comp Neurol 386: 358-378.

Ehrlich I, Humeau Y, Grenier F, Ciocchi S, Herry C, Lüthi A. 2009. Amygdala inhibitory circuits and the control of fear memory. Neuron 62: $757-771$.

Fanselow MS. 1980. Conditioned and unconditional components of post-shock freezing. Pavlov J Biol Sci 15: 177-182.

Ferry B, McGaugh JL. 2008. Involvement of basolateral amygdala alpha2-adrenoceptors in modulating consolidation of inhibitory avoidance memory. Learn Mem 15: 238-243.

Gray JA. 1978. The neuropsychology of anxiety. Br J Psychol 69: 417-434

$\mathrm{Hu}$ H, Real E, Takamiya K, Kang MG, LeDoux J, Huganir RL, Malinow R. 2007. Emotion enhances learning via norepinephrine regulation of AMPA-receptor trafficking. Cell 131: 160-173.

Johnson LR, Hou M, Ponce-Alvarez A, Gribelyuk LM, Alphs HH, Albert L, Brown BL, LeDoux JE, Doyère V. 2008. A recurrent network in the lateral amygdala: A mechanism for coincidence detection. Front Neural Circuits 2: 3. doi: 10.3389/neuro.04.003.2008.

Jones BE, Moore RY. 1977. Ascending projections of the locus coeruleus in the rat. II. Autoradiographic study. Brain Res 127: 25-53.

Jones LS, Gauger LL, Davis JN. 1985. Anatomy of brain alpha1-adrenergic receptors: In vitro autoradiography with [125I]-heat. J Comp Neurol 231: $190-208$.

LeDoux JE. 2000. Emotion circuits in the brain. Annu Rev Neurosci 23: $155-184$.

Lee HJ, Berger SY, Stidel O, Spiess J, Kim JJ. 2001. Post-training injections of catecholaminergic drugs do not modulate fear conditioning in rats and mice. Neurosci Lett 303: 123-126.

Maren S. 2001. Neurobiology of Pavlovian fear conditioning. Annu Rev Neurosci 24: 897-931.

McGaugh JL. 2004. The amygdala modulates the consolidation of memories of emotionally arousing experiences. Annu Rev Neurosci 27: $1-28$.
McGaugh JL, McIntyre CK, Power AE. 2002. Amygdala modulation of memory consolidation: Interaction with other brain systems. Neurobiol Learn Mem 78: 539-552.

Pitkänen A. 2000. Connectivity of the rat amygdaloid complex. In The amygdala: A functional analysis (ed. JP Aggleton), pp. 31-99. Oxford University Press, Oxford, UK.

Redmond DE Jr, Huang YH. 1979. Current concepts. II. New evidence for a locus coeruleus-norepinephrine connection with anxiety. Life Sci 25: 2149-2162.

Schiller D, Cain CK, Curley NG, Schwartz JS, Stern SA, LeDoux JE, Phelps EA. 2008. Evidence for recovery of fear following immediate extinction in rats and humans. Learn Mem 15: 394-402.

Shaban H, Humeau Y, Herry C, Cassasus G, Shigemoto R, Ciocchi S, Barbieri S, van der Putten H, Kaupmann K, Bettler B, et al. 2006. Generalization of amygdala LTP and conditioned fear in the absence of presynaptic inhibition. Nat Neurosci 9: 1028-1035.

Shin RM, Tsvetkov E, Bolshakov VY. 2006. Spatiotemporal asymmetry of associative synaptic plasticity in fear conditioning pathways. Neuron 52: $883-896$.

Shumyatsky GP, Tsvetkov E, Malleret G, Vronskaya S, Hatton M, Hampton L, Battey JF, Dulac C, Kandel ER, Bolshakov VY. 2002. Identification of a signaling network in lateral nucleus of amygdala important for inhibiting memory specifically related to learned fear. Cell 111: 905-918.

Sotres-Bayon F, Diaz-Mataix L, Bush DE, LeDoux JE. 2009. Dissociable roles for the ventromedial prefrontal cortex and amygdala in fear extinction: NR2B contribution. Cereb Cortex 19: 474-482.

Stutzmann GE, LeDoux JE. 1999. GABAergic antagonists block the inhibitory effects of serotonin in the lateral amygdala: A mechanism for modulation of sensory inputs related to fear conditioning. J Neurosci 19: RC8 (1-4).

Tanaka M, Yoshida M, Emoto H, Ishii H. 2000. Noradrenaline systems in the hypothalamus, amygdala and locus coeruleus are involved in the provocation of anxiety: Basic studies. Eur J Pharmacol 405: 397-406.

Tully K, Li Y, Tsvetkov E, Bolshakov VY. 2007. Norepinephrine enables the induction of associative long-term potentiation at thalamo-amygdala synapses. Proc Natl Acad Sci 104: 14146-14150.

Walker DL, Davis M. 2002. Quantifying fear potentiated startle using absolute versus proportional increase scoring methods: Implications for the neurocircuitry of fear and anxiety. Psychopharmacology (Berl) 164: $18-328$

Weisskopf MG, LeDoux JE. 1999. Distinct populations of NMDA receptors at subcortical and cortical inputs to principal cells of the lateral amygdala. J Neurophys 81: 930-934.

Received June 22, 2010; accepted in revised form July 27, 2010. 


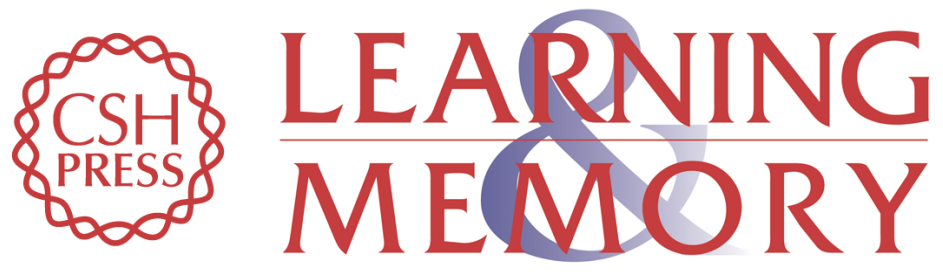

\section{Antagonism of lateral amygdala alpha1-adrenergic receptors facilitates fear conditioning and long-term potentiation}

Stephanie C. Lazzaro, Mian Hou, Catarina Cunha, et al.

Learn. Mem. 2010, 17:

Access the most recent version at doi:10.1101//m.1918210

References This article cites 38 articles, 5 of which can be accessed free at:

http://learnmem.cshlp.org/content/17/10/489.full.html\#ref-list-1

License

Email Alerting Receive free email alerts when new articles cite this article - sign up in the box at the Service top right corner of the article or click here. 